\title{
Jean Potocki à nouveau, Études réunies et présentées par Émilie Klene, Emiliano Ranocchi et Przemysław Witkowski
}

\section{Regina Bochenek Franczakowa}

\section{(2) OpenEdition}

\section{Journals}

Édition électronique

URL : https://journals.openedition.org/studifrancesi/4702

DOI : 10.4000/studifrancesi.4702

ISSN : 2421-5856

Éditeur

Rosenberg \& Sellier

\section{Édition imprimée}

Date de publication : 1 avril 2012

Pagination : 153-154

ISSN : 0039-2944

\section{Référence électronique}

Regina Bochenek Franczakowa, «Jean Potocki à nouveau, Études réunies et présentées par Émilie Klene, Emiliano Ranocchi et Przemysław Witkowski », Studi Francesi [En ligne], 166 (I | LVI) | 2012, mis en ligne le 30 novembre 2015, consulté le 19 novembre 2021. URL : http://journals.openedition.org/ studifrancesi/4702 ; DOI : https://doi.org/10.4000/studifrancesi.4702

Ce document a été généré automatiquement le 19 novembre 2021.

\section{cc) (†) $\odot$}

Studi Francesi è distribuita con Licenza Creative Commons Attribuzione - Non commerciale - Non opere derivate 4.0 Internazionale. 


\title{
Jean Potocki à nouveau, Études réunies et présentées par Émilie Klene, Emiliano Ranocchi et Przemysław Witkowski
}

\author{
Regina Bochenek Franczakowa
}

\section{RÉFÉRENCE}

Jean Potocki à nouveau, Études réunies et présentées par Émilie KLENE, Emiliano RANOcCHI et Przemysław wIткоwsкI, suivies de la première version du Manuscrit trouvé à Saragosse, dans une version modernisée de François ROSSET et Dominique TRIAIRE, Amsterdam-New York, Rodopi, 2010, pp. 434.

1 Depuis les toutes dernières éditions des œuvres de Jean Potocki, les chercheurs ne cessent de réexaminer celles-ci à la lumière des découvertes récentes de manuscrits. Ces recherches portent sur Le Manuscrit trouvé à Saragosse, mais aussi sur d'autres textes potockiens ainsi que sur la pensée et les divers faits de la vie de l'écrivain. Cet ouvrage rassemble les résultats de ces nouvelles recherches présentés lors d'un colloque qui s'est tenu à Cracovie en 2008. De plus, il réunit les travaux d'éminents spécialistes et ceux des jeunes chercheurs qui forment une nouvelle génération d'interprètes de l'œuvre de Potocki.

2 Le volume se compose de trois parties. Dans la première («Profils d'une œuvre multiple»), les auteurs des études abordent divers problèmes: l'Histoire primitive des peuples de la Russie de Potocki (1802) est examinée par le biais de sa genèse et de ses sources (Monika NIEWóJT, Potocki et Hérodote, pp. 9-26). Emiliano RANOcCHI compare deux manuscrits de Potocki, dont l'un inconnu, découvert par l'Auteur, d'un essai sur le Déluge («Nous avons collationné l'histoire des hommes avec celle de la nature»: un essai inconnu de Jean Potocki, pp. 27-47). Przemysław B. wiткоwsKi présente les résultats des 
recherches récentes sur les relations de Potocki vers la fin de sa vie avec la cour de Tulczyn (Jean Potocki et le théâtre de Tulczyn, pp. 49-63). Marek DE début de l'idée subversive dans l'œuvre de Potocki, pp. 65-74) analyse deux parades jouées dans le château de tan'cut en 1792, qui illustrent la formation des idées subversives (sociales et religieuses) de l'écrivain. Yves citTon aborde une piécette de Potocki afin d'en dégager les éléments d'une théorisation de la démocratie, sans oublier qu'il s'agit d'un texte pour amuser le public (Société du spectacle et démocratie de la parade dans "Cassandre démocrate" de Jean Potocki, pp. 75-100). Aux yeux d'Émilie KLENE, Jean Potocki adopte la conception libertine de la connaissance, ce qui fait de lui un «écrivain d'une radicale modernité» (Les "Voyages" de Potocki: regard d'un libertin, pp.101-110). Adam ŁUKASZEWICZ retrace le voyage de Potocki en Égypte et présente son livret Voyage en Égypte publié en 1788 en français (Jean Potocki au pied des pyramides, pp. 111-120). Janusz RYBA brosse le portrait d'un personnage pittoresque - le serviteur de Potocki d'origine turque (Ibrahim, le Turc de Jean Potocki, pp. 121-129). Jean-Marc ROHRBASSER examine le «style géométrique» de l'écrivain ( $2^{\mathrm{e}}$ partie d'un ensemble), qui prouve que ce style est une manière d'écrire, de penser et représenter le monde "comme susceptible de mathématisation» (Le style géométrique de Potocki (2), pp. 131-182).

3 La deuxième partie réunit des analyses du Manuscrit trouvé à Saragosse. Dominique TRIAIRE relève et examine les personnages juifs représentés dans ce roman, en particulier l'histoire du cabaliste du début et celle de la maison d'Uzeda (Les personnages juifs du "Manuscrit trouvé à Saragosse", pp. 185-194). Lorenz FRISCHKNECHT démontre que le chef-d'œuvre potockien est un «roman du discours et un roman de l'effet du discours» ("Comme j'avais beaucoup entendu parler de tout cela...»: les effets du récit dans le "Manuscrit trouvé à Saragosse", pp.195-211). Selon Luc FRAISSE, c'est autour du personnage de Velasquez qu'est centrée l'interrogation du romancier sur la forme à donner à son œuvre, qui illustre l'évolution vers un roman «par définition non résolu» ("Je ne sais plus qui parle ou qui écoute»: Velasquez et le problème du roman, pp. 213-228). Isabella MATAZZI examine le thème du voyage, dans sa dimension fantastique, mais aussi philosophique, liée à l'illuminisme (Histoires de voyageurs enchantés. Jean Potocki et le thème du voyage fantastique au XVIII siècle, pp. 229-237). Paul PELCKMANS analyse la représentation et le sens des épisodes du roman qui se passent outre-Atlantique et conclut que le roman respire «la bonne conscience coloniale» typique $\mathrm{du} \mathrm{XIX}^{\mathrm{e}}$ plutôt que du $\mathrm{XVIII}^{\mathrm{e}}$ siècle ( $L e$ Nouveau Monde du "Manuscrit", pp. 239-252). Françoise DERVIEUX interprète le roman potockien en confrontation avec Lamekis de Mouhy: même s'il n'y a que «rencontre» de deux textes, le fait est fort intéressant à considérer du point de vue de l'intrigue, l'espace, le temps, les personnages et la structure d'enchâssement ("Lamekis" de Mouhy et le "Manuscrit trouvé à Saragosse", pp. 253-265). Jan HERMAN considère une autre rencontre possible, voire troublante, vu les analogies et les ressemblances, du texte de Potocki et celui d'un auteur peu connu, Montjoye: rencontre qui mène à reconsidérer la genèse textuelle chez le premier ("Manuscrit trouvé à Saragosse" et Manuscrit trouvé au Mont Pausilype". Sur un problème de genèse textuelle chez Potocki, pp. 267-279). François ROSSET réfléchit sur le rapport entre la vie et l'œuvre, qui dans le cas de Potocki est particulièrement délicat et complexe (Biographie et lecture du "Manuscrit trouvé à Saragosse", pp. 281-288). L'ensemble des études est clos par l'analyse d'une traduction polonaise du Manuscrit au XIX siècle (Anna WASILEWSKA, Dans les caves de Chatacz. Le "Manuscrit trouvé à Saragosse" dans la traduction d'Edmund Chojecki 160 ans après, pp. 289-306). 
4 La troisième partie du volume contient, en annexes, des textes inédits de Jean Potocki: Recueil raisonné des plus anciennes notions historiques; Essai sur le déluge; enfin "Manuscrit trouvé à Saragosse" (Première version), celle-ci précédée d'une présentation par François Rosset et Dominique Triaire. Les deux chercheurs ont décidé de livrer ici une édition modernisée de la "version de 1794», accessible uniquement aux spécialistes, sur le CDRom accompagnant le volume IV-2 de l'édition des Euvres complètes de Potocki parue chez Peeters. Excellente décision qui élargit le lectorat de cette première version, inconnue, du chef-d'œuvre potockien. 